\title{
Thymic langerhans cell histiocytosis in children: A case report ${ }^{*}$
}

\author{
Marie Poncelet $^{\text {\#\#} \text {, Camille Chabert }}{ }^{2}$, Jean Pierre Pracros ${ }^{2}$, Perrine Marec Berard ${ }^{1}$ \\ ${ }^{1}$ Pediatric Institute of Hematology and Oncology, Institut d'Hématologie et d'Oncologie Pédiatrique (IHOP), Lyon, France \\ ${ }^{2}$ Pediatric Unit of Radiology, Hôpital Femme Mère Enfant (HFME), Lyon, France \\ Email: "poncelet.marie@yahoo.fr
}

Received 14 August 2012; revised 17 September 2012; accepted 5 October 2012

\begin{abstract}
Langerhans cell histiocytosis has long been described as a rare systemic disorder involving the proliferation of Langerhans cells with formation of granuloma. The disease may be localised or diffuse. Typical forms of the disease involving the bone, the skin or the pituitary gland have been well described whereas others, such as thymic histiocytosis, are still poorly understood. Here, we report a case of isolated Langerhans cell histiocytosis of the thymus in an infant with nonspecific symptoms. We provide a description of the disease and discuss patient management.
\end{abstract}

Keywords: Langerhans Cell Histiocytosis; Children; Thymus

\section{INTRODUCTION}

Langerhans Cell Histiocytosis (LCH) is a complex systemic disorder characterized by an abnormal proliferation of Langerhans cells, generally organized in granulomas. The estimated prevalence is between 1 and 2 per 100,000 population [1]. The organs most frequently involved are the bone, the skin, the pituitary gland, the lung and, less commonly, the hematopoietic system, the liver and the central nervous system [2]. Thymus involvement is rare. LCH typically occurs in children as part of a multifocal, multisystem process [3,4]. Only few reports of isolated tumours involving the thymus have been published in adults, either in association with coexistent myasthenia gravis [5,6], low-grade leiomyosarcoma [7] or multilocular thymic cyst [8]. In the literature we found only a single case of a child who presented an isolated thymic $\mathrm{LCH}$, mimicking lymphoma [9].

\section{OBSERVATION}

The patient was a 9-month-old child admitted to hospital

*Conflict of interest: The authors haven't any financial relationship with anyone about this research.

${ }^{\#}$ Corresponding author. for investigation of a 2-month history of recurrent fever, especially at night, associated with intermittent cough. Blood tests showed an elevated leukocyte count $(20 \mathrm{G} / \mathrm{L})$ with microcytic anaemia (haemoglobin $85 \mathrm{~g} / \mathrm{L}$ ), $664 \mathrm{G} / \mathrm{L}$ platelets and $114 \mathrm{mg} / \mathrm{L}$ C-reactive protein. Chest X-ray revealed an enlargement of the thymus (Figure 1), and many diffuse, multicentric micro-calcifications were detected by ultrasound (Figure 2). The patient underwent complementary Computed Tomographic (CT)-scan evaluation (Figure 3) and diagnosis was confirmed by histological examination of transparietal fine-needle aspiration biopsies. Histological sections revealed large cells characterized by grooved, convoluted, off-centred nuclei and abundant eosinophilic cytoplasm, associated with high polynuclear cell levels. The cells were strongly reactive for CD1a and moderately expressed S100 protein. These findings were consistent with the diagnosis of Langerhans cell granuloma or histiocytosis X.

Subsequent staging revealed no other disease site. A combination therapy with vinblastine $\left(\mathrm{Velbe}^{\mathbb{B}}\right)$ and steroids was administered weekly for 6 consecutive weeks, as recommended by current French guidelines. Radiological control after 6 weeks showed complete response to treatment (Figure 4). Maintenance treatment consisted of one course every 3 weeks for 6 months, with control chest X-ray every 2 months. CT-scan examination after the end of treatment confirmed complete remission of the disease (Figure 5).

\section{DISCUSSION}

Because of its rarity, $\mathrm{LCH}$ remains poorly understood. The disease was first described in 1953 by Lichtenstein under the term "histiocytosis X". This entity encompassed a group of rare syndromes of unknown aetiology such as eosinophilic granuloma, Letterer-Siwe disease or Hand-Schuller-Christian disease [9]. In 1987, because of the presence in the tumour of Langerhans cells - a subgroup of dendritic histiocytes initially described by Paul Langerhans in 1868 [10], the name was changed to "Langerhans cell histiocytosis [11]". 


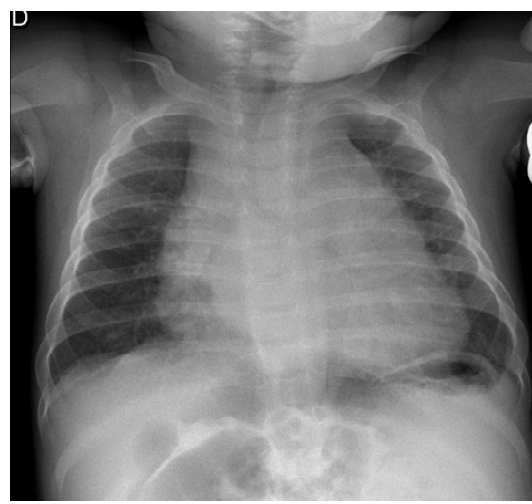

Figure 1. Mediastinal enlargement on chest radiograph at diagnosis.

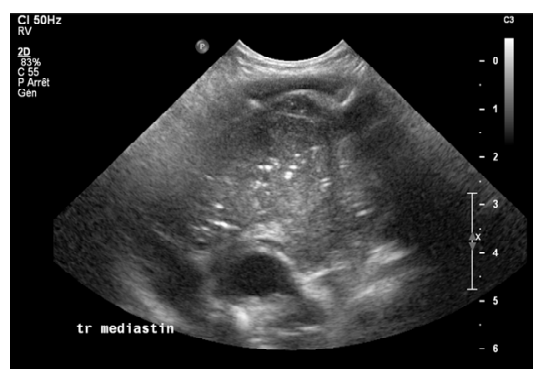

Figure 2. Ultrasound image of the thymus at diagnosis: heterogeneous tissue with numerous microcalcifications.

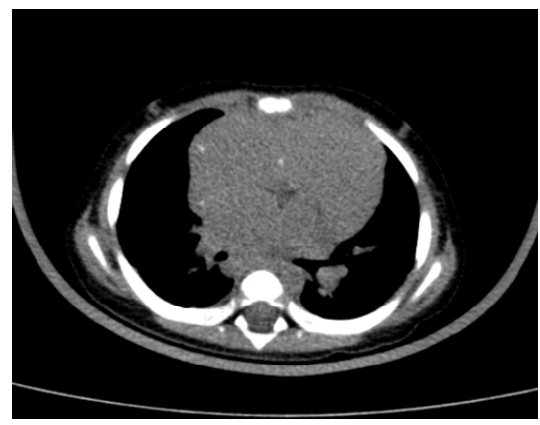

Figure 3. Chest CT-scan at diagnosis with evidence of mediastinal enlargement and calcifications.

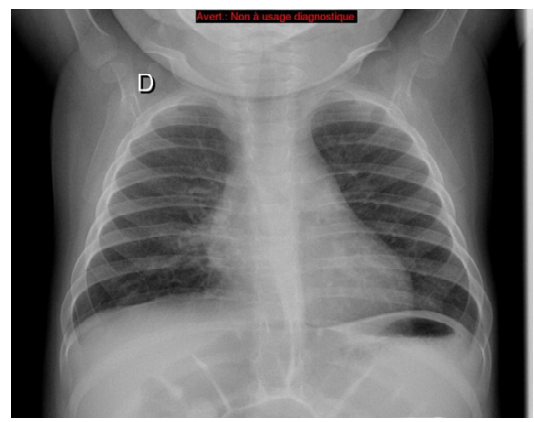

Figure 4. Chest radiograph after 6 weeks of treatement: no mediastinal enlargement and calcification left.

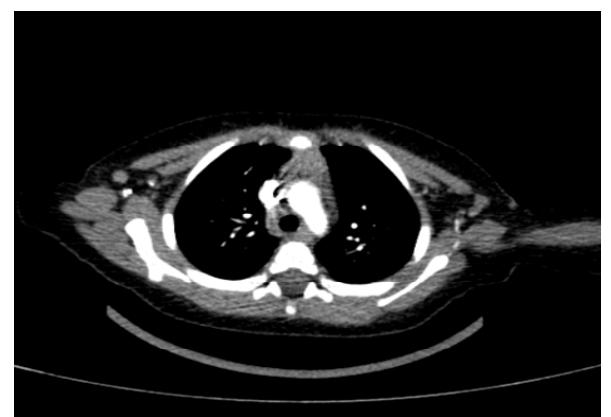

Figure 5. Chest radiograph and chest CT-scan at the end of treatement: no mediastinal enlargement and calcification left.

The disease pattern, i.e. whether LCH is localized or occurs as part of a multisystem process, is known to be a marker of severity [2]. In patients with high-risk multisystem disease, the most effective treatment strategy involves a combination of chemotherapy and steroids to limit the risk of complications and improve outcome. By extension, this treatment tends to be also applied in patients with lower risk, localized LCH. Reports of LCH within the thymus are less frequent than within the bone, the skin or the endocrine system. Although thymic lesions are commonly reported in the setting of multisystem disease [12], isolated forms are rare. Indeed, in a series of $14 \mathrm{LCH}$ patients with thymic involvement, either at presentation or during the course of the disease, reported by Junewick and Fitzgerald, 7 had multisystem involvement, 1 had unisystem but multifocal involvement and 6 had isolated unifocal disease [12]. Several studies have described thymic LCH as an enlargement of the mediastinum due to increased thymic volume. The thymus is enlarged, with lobulated/nodular contours and heterogeneous ultrasound pattern, and possibly contains liquid cysts and/or calcifications $[12,13]$.

As demonstrated here and in other published series (Patient with superior vena cava obstruction at initial diagnosis, for instance [14]), the presentation of the disease is highly variable, which makes diagnosis extremely challenging. In our patient, an history of recurrent childhood diseases led to the radiological examination of the chest which revealed the tumour. Clinical and radiological correlation is essential for diagnosis. Because of these diagnostic difficulties, it is hypothesized that the incidence of LCH may be underestimated, as for instance in very young children with typical thymic enlargement associated or not with non-specific episodes of fever and bronchial or pulmonary infection. The incidental discovery of a thymic LCH in young adult patients with myasthenia gravis is also in favour of this hypothesis [5,6]. Based on these observations, the actual contribution of chemotherapy to the treatment of patients with localized LCH may appear questionable. These patients are likely to have 
a good response to treatment $[13,14]$; however, one may wonder whether they actually derive a benefit from chemotherapy or whether spontaneous regression can be expected [15].

\section{CONCLUSION}

LCH with thymic involvement is a rare but well described disease. Typically, patients with unifocal tumours have a good prognosis and respond well to chemotherapy, although one may question the appropriateness of treating these patients who may well recover spontaneously. The incidence of LCH is probably underestimated because diagnosis is hampered by the lack of specific clinical presentation and poor knowledge of radiological manifestations of the disease.

\section{REFERENCES}

[1] Donadieu, J. and Tazi, A. (2007) Langerhans cell histiocytosis. Orphanet.

http://www.orpha.net/consor/cgi-bin/OC Exp.php?Expert $=389.0 \& \ln \mathrm{g}=\mathrm{EN}$

[2] Nguyen, K. and Tazi, A. (2006) Histiocytose langerhansienne de l'adulte. La Revue du Praticien, 56, 1863-1871.

[3] Bove, K., Hurtubise, P. and Wong, K.Y. (1985) Thymus in untreated systemic histiocytosis X. Pediatric Pathology, 4, 99-115. doi:10.3109/15513818509025907

[4] Tsunematsu, Y., Koide, R., Watanabe, S., Takahashi, H., Morikawa, Y. and Shimizu, K. (1984) A clinicopathological study of histiocytosis X. Japanese Journal of Clinical Oncology, 14, 633-646.

[5] Gilcrease, M.Z., Rajan, B., Ostrowski, M.L., Ramzy, I. and Schwartz, M.R. (1997) Localized thymic Langerhans' cell histiocytosis and its relationship with myasthenia gravis: Immunohistochemical, ultrastructural, and cytometric studies. Archives of Pathology \& Laboratory Medicine, 121, 134-138.

[6] Bramwell, N.H. and Burns, B.F. (1986) Histiocytosis X of the thymus in association with myasthenia gravis. American Journal of Clinical Pathology, 86, 224-227.

[7] Lee, B.H., George, S. and Kutok, J.L. (2003) Langerhans cell histiocytosis involving the thymus. A case report and review of the literature. Archives of Pathology \& Laboratory Medicine, 127, 294-297.

[8] Wakely, P. and Suster, S. (2000) Langerhans' cell histiocytosis of the thymus associated with multilocular thymic cyst. Human Pathology, 31, 1532-1535. doi:10.1053/hupa.2000.20410

[9] Yağci, B. and Varan, A. (2008) Thymic langerhans cell histiocytosis mimicking lymphoma. Pediatric Blood \& Cancer, 51, 833-835. doi:10.1002/pbc. 21690

[10] Langerhans, P. (1868) Uber die nerven der menschlichen haut. Virchows Arch a Pathol Anat Histopathology, 44, 325-337.

[11] Lichtenstein, L. (1953) Histiocytosis X: Integration of eosinophilic granuloma of bone, letterer-siwe disease and schuller-christian disease as related manifestations of a single nosologic entity. AMA Archives of Pathology, 56, 84-102.

[12] Heller, G.D., Haller, J.O., Berdon, W.E., Sane, S. and Kleinman, P.K. (1999) Punctate thymic calcification in infants with untreated Langerhans' cell histiocytosis: Report of four new cases. Pediatric Radiology, 29, 813-815. doi:10.1007/s002470050702

[13] Junewick, J.J. and Fitzgerald, N.E. (1999) The thymus in Langerhans' cell histiocytosis. Pediatric Radiology, 29, 904 907. doi:10.1007/s002470050722

[14] Trusen, A., Beissert, M., Hebestreit, H., Marx, A. and Darge, K. (2003) Fibrosing mediastinitis with superior vena cava obstruction as the initial presentation of Langerhans' cell histiocytosis in a young child. Pediatric Radiology, 33, 485488. doi:10.1007/s00247-003-0929-2

[15] Hatakeyama, N., Hori, T., Yamamoto, M., Sogawa, I., Inazawa, N., Tsutsumi, H. and Suzuki, N. (2009) An infant with self-healing cutaneous Langerhans' cell histiocytosis followed by isolated thymus relapse. Pediatric Blood \& Cancer, 53, 229-231. doi: $10.1002 /$ pbc. 22026 